\title{
Implementasi Workshop Blended Learning Menggunakan E-Book Lesson Plan Berbasis Hypercontent Dalam Meningkatkan Kompetensi Guru
}

\author{
Siti Raihan \\ Prodi Pendidikan Guru Sekolah Dasar, Fakultas Ilmu Pendidikan, Universitas Negeri Makassar \\ sitiraihan@unm.ac.id
}

\begin{abstract}
ABSTRAK
Peningkatan kualitas Pendidikan di Indonesia berdampak pada kebutuhan peningkatan kualitas guru. Sebagai pendidik professional, guru berperan dalam keberhasilan penyelenggaraan pendidikan. Rencana pembelajaran (lesson plan) menjadi strategi guru memanajemen proses pembelajaran. Kompetensi guru dalam mengembangkan RPP dibutuhkan khususnya dalam menerapkan pembelajaran berbasis pendekatan saintifik dan berkarakter. Guru perlu menguasai konsep pengembangan RPP saintifik berkarakter untuk pembelajaran daring maupun luring. Guru perlu selalu difasilitasi dalam meningkatkan kompetensinya.Tersedianya e-book sebagai bahan pelatihan, perlu diuji efektivitasnya agar tepat guna dalam pemanfaatannya meningkatkan kompetensi guru. E-book berbasis hypercontent dipilih karena memenuhi kriteria bahan pelatihan yang fleksibel, dan efisien untuk dapat digunakan secara daring dan luring karena memiliki beragam fitur (hypercontent). Oleh karena itu, diharapkan melalui penelitian ini mampu mengetahui implementasi workshop blended learning menggunakan $e$ book lesson plan berbasis hypercontent dalam meningkatkan kompetensi guru mengembangkan RPP saintifik berkarakter. Penelitian pre-experimental jenis One-Group Pretest-Posttest Design ini dikemas dalam bentuk kegiatan workshop blended learning dengan subjek penelitian salah satu kelompok guru MGMP di Kota Jambi. Hasil evaluasi dengan uji normalitas, uji homogenitas, dan uji n-gain menujukkan bahwasanya terjadi peningkatan kompetensi guru dalam mengembangkan RPP saintifik berkarakter berdasarkan hasil analisis data kualitas RPP guru sebelum (pretest) dan sesudah (posttest) implementasi workshop blended learning menggunakan e-book leasson plan berbasis hypercontent.
\end{abstract}

Kata kunci: Workshop, Blended Learning, E-Book Lesson Plan, Hypercontent, Kompetensi Guru

\section{ABSTRACT}

Improving the quality of education in Indonesia has an impact on the need to improve teacher quality. As professional educators, teachers play a role in the successful delivery of education. The lesson plan (lesson plan) becomes the teacher's strategy for managing the learning process. Teacher competence in developing lesson plans is needed, especially in applying learning based on a scientific approach and character. Teachers need to master the concept of developing character scientific lesson plans for online and offline learning. Teachers need to always be facilitated in increasing their competence. The availability of e-books as training materials, their effectiveness needs to be tested so that they are effective in their utilization to increase teacher competence. Hypercontent-based e-books were chosen because they met the criteria for flexible training materials, and were efficient to be used online and offline because they had various features (hypercontent). Therefore, it is hoped that this research will be able to find out the implementation of blended learning workshops using hypercontentbased e-book lesson plans in improving teacher competence in developing character-based scientific lesson plans. This pre-experimental research type One-Group Pretest-Posttest Design is packaged in the form of a blended learning workshop with the research subject of one of the MGMP teacher groups in Jambi City. The evaluation results with the normality test, homogeneity test, and n-gain test showed that there was an increase in teacher competence in developing character-based scientific lesson plans based on the results of data analysis on the quality of teacher lesson plans before (pretest) and after (posttest) the implementation of blended learning workshops using the e-book Leasson. hypercontent based plan.

Keywords: Workshop, Blended Learning, E-Book Lesson Plan, Hypercontent, Teacher Competence 


\section{PENDAHULUAN}

Pendidikan merupakan suatu upaya dalam menciptakan sumber daya manusia yang berkualitas dan berkompeten sesuai kebutuhan masyarakat dan dunia kerja. Peningkatan kualitas Pendidikan di Indonesia berdampak pada kebutuhan peningkatan kualitas guru. Peningkatan kualitas guru yang dimaksud meliputi empat kompetensi guru, yakni kompetensi pedagogik, kompetensi professional, kompetensi kepribadian, dan kompetensi sosial. Oleh karena itu, penyelenggaraan Pendidikan tidak telepas dari peran utama seorang guru (Pagarra et al., 2020).

Guru adalah pendidik profesional dengan tugas utama mendidik, mengajar, membimbing, mengarahkan, melatih, menilai, dan mengevaluasi peserta didik pada pendidikan anak usia dini jalur pendidikan formal, pendidikan dasar, dan pendidikan menengah (Undang-undang Nomor 14 Tahun 2005). Sebagai pendidik professional, peran guru berpengaruh terhadap proses pembelajaran khususnya dalam pencapaian tujuan Pendidikan (Pratama \& Lestari, 2020).

Berdasarkan standar proses dalam Permendiknas Nomor 41 Tahun 2007 diketahui bahwa perencanaan proses pembelajaran mensyaratkan pendidik pada satuan pendidikan untuk mengembangkan rencana pembelajaran. Rencana pembelajaran (lesson plan) menjadi strategi guru dalam memanajemen proses pembelajaran. Adapun kualitas perangkat pembelajaran akan mencerminkan kualitas proses Pendidikan berpedoman pada kurikulum yang berlaku yakni kurikulum 2013 (Raihan et al., 2018).

Kurikulum 2013 memfasilitasi siswa belajar aktif. Menurut Wicaksono et al (2020), pendekatan saitifik memfasilitasi pembelajaran berpusat pada siswa. Dalam Menyusun dan merencanakan pembelajaran kurikulum 2013 berbasis pendekatan saintifik dan berkarakter, RPP harus memuat $5 \mathrm{M}$ aktivitas pembelajaran, yakni: mengamati, menanya, mengassosiasi/ mengumpulkan data, dan mengkomunikasikan. Pembelajaran dengan pendekatan saintifik diharapkan mampu memfasilitasi siswa belajar dengan pola berpikir tingkat tinggi (HOTS).

Adanya pandemi covid-19 berdampak pada perubahan kebijakan terkait pelaksanaan Pendidikan dan transformasi kurikulum 2013. Pelaksanaan pembelajaran maupun pelatihan perlu mempertimbangkan kebijakan protocol kesehatan yang berlaku di setiap daerah di Indonesia. Oleh karena itu perlu adanya upaya yang dilakukan agar guru-guru dapat selalu difasilitasi dalam meningkatkan kompetensi khususnya pada pengembangan perangkat pembelajaran salah satunya RPP. RPP menjadi fokus utama dalam mengembangkan sebuah perangkat pembelajaran dikarenakan memuat gambaran kualitas pelaksanaan pembelajaran yang akan dilaksanakan oleh guru. Guru harus menguasai kemampuan menggunakan teknologi dan mengembangkan perangkat pembelajaran berbasis pada student centered learning. Disamping itu, guru juga harus memahami karakteristik pada setiap ruang belajar synchronous (tatap muka dan tatap maya) dan asynchronous (self-directed learning dan collaborative learning) (Meishanti, 2020). Adanya revisi kurikulum 2013 hingga edisi revisi tahun 2019 dan penyesuaian kurikulum 2013 menjadi kurikulum fleksibel mengakibatkan kendala bagi guru dalam memahami konsep pengembangan RPP berbasis pendekatan saintifik berkarakter untuk pembelajaran luring maupun daring.

Semakin berkembangnya ilmu pengetahuan dan teknologi (IPTEK) di era 4.0 menuju society 5.0 serta yang berdampak pada terjadinya disrupsi dibidang Pendidikan. Tidak dapat dipungkiri bahwasanya pelaksanaan Pendidikan dihadapkan pada masa dimana manusia akan menjadi pusatnya (human centered) dengan berbasis teknologi (technology based) (Hotimah et al., 2020). Oleh karena itu, peran serta teknologi sebagai alat bantu pembelajaran sulit dipisahkan. Dengan beragam software yang berkembang dalam dunia pendidikan telah banyak menghasilkan beragam $e$-book sebagai bahan ajar untuk siswa dan bahan pelatihan untuk guru. Namun penggunaan e-book tersebut sebagai bahan pelatihan perlu menyesuaikan dengan kebutuhan dan diketahui efektivitasnya agar tepat guna.

Berdasarkan latar belakang tersebut, diketahui bahwa pentingnya kompetensi guru didasarkan pada peran guru sebagai agen pendidikan yang perlu selalu difasilitasi khususnya dalam hal peningkatan kompetensi. Banyak bahan pelatihan yang tersedia dalam bentuk e-book, namun perlu diketahui efektivitasnya agar tepat guna dalam pemanfaatannya meningkatkan kompetensi guru khususnya dalam mengembangkan RPP saintifik berkarakter (lesson plan). Pada penelitian ini e-book berbasis hypercontent dipilih karena dianggap memenuhi karakteristik bahan pelatihan yang dapat digunakan bukan hanya saat tatap muka melainkan sebagai sumber belajar mandiri bagi guru karena 
memiliki fitur teks, gambar, video, audio, dan animasi yang beragam (hypercontent). Oleh karena itu, diharapkan melalui penelitian eksperimen ini mampu mengetahui Implementasi workshop blended learning menggunakan e-book lesson plan berbasis hypercontent dalam meningkatkan kompetensi guru mengembangkan RPP saintifik berkarakter.

\section{METODE PENELITIAN}

Penelitian ini merupakan penelitian pre-experimental jenis One-Group PretestPosttest Design. Subjek pada penelitian ini adalah guru-guru pada salah satu kelompok MGMP mata pelajaran IPA di Kota Jambi. Metode pengambilan sampel menggunakan random sampling. Penelitian ini menggunakan pendekatan evaluasi sumatif terhadap hasil atau produk RPP pendekatan saintifik berkaraker. Instrumen yang digunakan adalah angket dengan skala likert untuk mengukur kualitas RPP berbasis pendekan saintifik berkarakter. Pelaksanaan penelitian dikemas dalam kegiatan workshop blended learning menggunakan bahan pelatihan dalam bentuk e-book lesson plan sebagai sumber belajar yang digunakan sampel. Workshop blended learning dibagi menjadi dua sesi yakni tatap muka dan pembimbingan online (whatsapp). Analisis data yang dilakukan meliputi uji normalitas, uji homogenitas dan uji $N$-gain untuk mengetahui peningkatan kompetensi guru dalam mengembangkan RPP berbasis pendekatan saintifik berkarakter.

HASIL \& PEMBAHASAN
Peningkatan
mengembangkan RPP

saintifik berkarakter dilaksanakan melalui kegiatan workshop blended learning dengan waktu pelaksanaan 34 JP. Pelaksanaan workshop dibagi kedalam dua sesi, yakni sesi tatap muka, dan sesi pembimbingan online. Kegiatan workshop diawali dengan mengumpulkan RPP yang biasa digunakan guru pada pengajaran disekolahnya. Pengumpulan RPP sebelum kegiatan selanjutnya akan digunakan peneliti untuk memperoleh data kualitas RPP guru sebelum pelaksanaan workshop (pretest). Peneliti menjelaskan sistematika kegiatan workshop blended learning dengan memanfaatkan bahan pelatihan berupa e-book lesson plan berbasis hypercontent.

Di akhir kegiatan, peneliti membuka pertanyaan tentang bagaimana pemahaman peserta dan progress pengembangan RPP yang peserta kerjakan selama pelaksanaan kegiatan workshop berlangsung menggunakan bahan pelatihan berupa e-book lesson plan berbasis hypercontent. Kemudian meminta peserta atau subjek penelitian untuk menyelesaikan dan mengumpulkan RPP yang telah dikembangkan sebagai hasil atau produk kegiatan workshop untuk selanjutnya dianalisis. Tujuannya ialah untuk mengetahui efektivitas e-book lesson plan berbasis hypercontent (pretest-posttest data kualitas RPP Guru). Analisis data pada penelitian ini menggunakan uji normalitas, uji homogenitas, dan uji $\mathrm{N}$-Gain.

Uji normalitas dilakukan untuk mengetahui data tersebut berdistribusi normal atau tidak, sehingga langkah selanjutnya tidak menyimpang dari kebenaran dan dapat dipertanggungjawabkan. Uji normalitas diujikan dengan menggunakan uji One-Sample Kolmogorov-Smirnov Test dengan bantuan SPSS 16 (tabel 1).

Tabel 1. Hasil Uji Normalitas Data Kualitas RPP Berbasis Pendekatan Sainfitik Berkarakter One-Sample Kolmogorov-Smirnov Test

\begin{tabular}{|ll|l|l|}
\hline & & Pretest & Posttest \\
\hline$N$ & & 30 & 30 \\
Normal Parameters $^{a}$ & Mean & 85.8167 & $1.1063 E 2$ \\
& Std. Deviation & 1.62143 & 5.96966 \\
Most Extreme Differences & Absolute & .159 & .194 \\
& Positive & .159 & .194 \\
& Negative & -.077 & -.139 \\
Kolmogorov-Smirnov Z & & .873 & 1.063 \\
Asymp. Sig. (2-tailed) & & .431 & .209 \\
\hline
\end{tabular}

Berdasarkan Tabel 1 diperoleh data hasil uji normalitas dengan nilai signifikansi pretest kualitas RPP guru adalah $0,05<0,431$ sehingga data pretest tersebut berdistribusi 
normal, nilai signifikansi untuk posttest kualitas RPP guru adalah $0,05<0,209$, sehingga data posttest berdistribusi normal. Jadi dapat disimpulkan bahwa data pretest dan posttest kualitas RPP guru tersebut sama-sama memiliki nilai signifikansi yang berdistribusi normal.

Setelah melakukan uji normalitas, maka peneliti melakukan uji homogenitas varian populasi untuk memperoleh asumsi bahwa sampel penelitian berasal dari populasi yang homogen atau tidak. Uji homogenitas dilakukan dengan menyelidiki apakah ketiga kelompok data kreativitas mempunyai varians yang sama atau tidak.

Pada penelitian ini, analisis homogenitas menggunakan uji One Way Anova yang berbantuan SPSS 16. Hasil pengujian homogenitas disajikan pada tabel 2.

Tabel 2. Hasil Uji Homogenitas Data Kualitas RPP Berbasis Pendekatan Sainfitik Berkarakter

Test of Homogeneity of Variances

\begin{tabular}{|l|l|l|l|l|}
\hline & Levene Statistic & $d f 1$ & $d f 2$ & Sig. \\
\hline Pretest RPP & $1.546^{a}$ & 6 & 19 & .217 \\
Posttest RPP & $1.763^{b}$ & 6 & 19 & .161 \\
\hline
\end{tabular}

Berdasarkan Tabel 2 diperoleh nilai signifikansi pretest RPP (sig) sebesar 0,217. Karena nilai signifikansi (sig) 0,05<0,217 maka dapat disimpulkan bahwa varian pretest kualitas RPP guru tersebut adalah sama atau homogen. Sedangkan untuk posttest kualitas RPP guru memperoleh nilai signifikansi (sig) $0,05<1,61$, sehingga dapat disimpulkan varian posttest adalah homogen.

Peningkatan kompetensi guru mengembangkan RPP diperoleh dari nilai

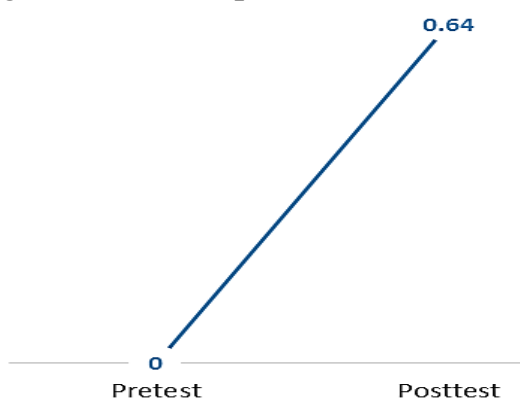

kualitas RPP guru sebelum (pretest) dan setelah (posttest) pelaksanaan workshop blended learning menggunakan e-book lesson plan berbasis hypercontent. Sehingga apabila dibandingkan, maka akan terlihat perbedaan hasil yang diperoleh dari uji $N$-Gain, yakni peningkatan kualitas RPP pretest-posttest sebesar 0,64 dengan kategori sedang (gambar 1).

Gambar 1. Hasil Uji Normalized Gain (N-Gain) Peningkatan Kompetensi Guru Mengembangkan RPP Berbasis Pendekatan Sainfitik Berkarakter

Menurut Hasjiandito, et al (2014), bahwa perangkat pembelajaran juga perlu diukur tingkat keefektifannya. Efektivitas ebook lesson plan berbasis hypercontent dapat dilihat dari hasil peningkatan kualitas RPP guru sebelum (pretest) dan setelah implementasi (posttest). Dari hasil analisis data diketahui peningkatan kualitas RPP guru pretest-posttest menggunakan uji n-gain sebesar 0,64 dengan kategori sedang, hal tersebut membuktikan bahwa implementasi e-book lesson plan berbasis hypercontent dapat meningkatkan kompetensi guru IPA dalam merancang RPP.

Berdasarkan temuan hasil penelitian diketahui bahwa penggunaan e-book lesson plan pada workshop blended learning mampu meningkatkan kompetensi guru dalam merancang RPP pendekatan saintifik berkarakter yang dapat dilihat pada diagram (gambar 2). 


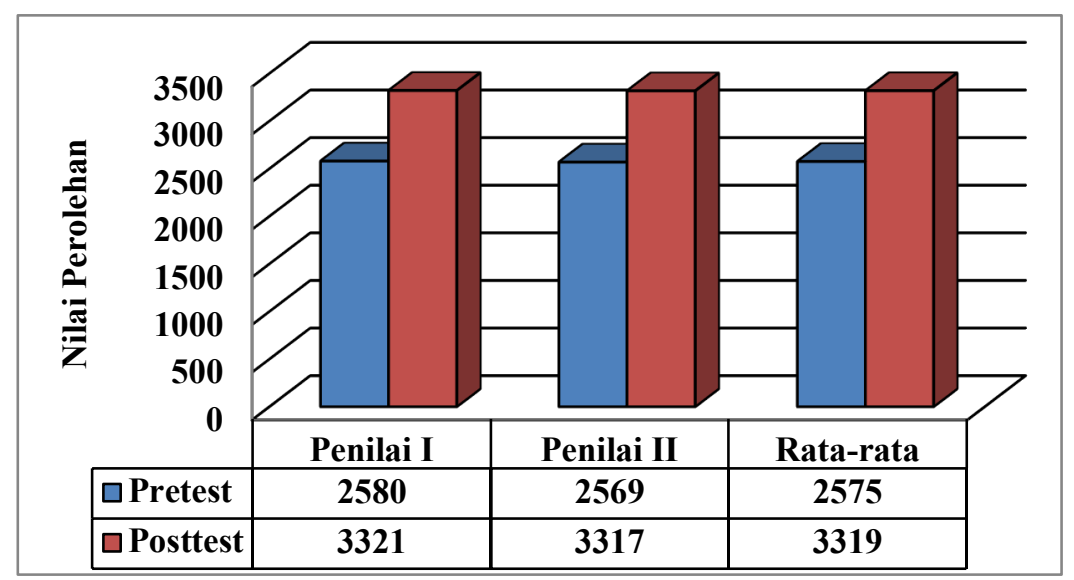

Gambar 2. Diagram Peningkatan Kompetensi Guru Mengembangkan RPP Berbasis Pendekatan Sainfitik Berkarakter

Efektivitas e-book lesson plan berbasis hypercontent yang digunakan sampel sebagai sumber bacaan digital atau bahan ajar multimedia juga diungkapkan pada penelitian lain yang serupa, yakni: 1) kualitas media $e$ book sangat layak, meliputi format, kualitas, kejelasan dan kemenarikan berdasarkan validitas, kepraktisan, dan keefektifan (Raihan et al, 2018; Eskawati \& Sanjaya, 2012; Ghofur \& Kustijono, 2015; Nugraha dan Wasis, 2014; Mawarni \& Muhtadi, 2017; Fuada et al, 2017); 2) aspek keefektifan dalam e-book ini juga terpenuhi, terbukti dengan skor yang diperoleh melalui pretest-posttest yang menunjukkan angka signifikan (Megawati, 2014; Susanto et al, 2016); dan 3) aspek interaktif dari bahan ajar e-book ini adalah penyajian materi dan implikasinya dalam kehidupan sehari-hari dalam bentuk video yang dapat diamati pengguna sebagai informasi dalam memahami (Munawwarah et al, 2017; Puspitasari \& Rakhmawati, 2013; Munwarah \& Buditjahtanto, 2016; Humairoh dan Wasis, 2015; Rodríguez et al, 2018; Vassiliou \& Rowley, 2008; Mark et al, 2016).

\section{KESIMPULAN \& SARAN}

Berdasarkan penelitian efektivitas e-book lesson plan berbasis hypercontent yang dilaksanakan dalam bentuk workshop blended learning dapat disimpulkan bahwa terdapat peningkatan kualitas RPP guru, sebelum pelaksanaan workshop (pretest) dan sesudah pelaksanaan workshop (posttest). Dengan demikian, penggunaan e-book lesson plan berbasis hypercontent pada pelaksanaan workshop blended learning terbukti efektif untuk meningkatkan kemampuan guru dalam mengembangkan RPP saintifik berkarakter berdasarkan hasil analisis data menggunakan uji normalitas, uji homogenitas dan uji n-gain.

Saran penelitian ini hendaknya penggunaan bahan pelatihan dalam bentuk ebook berbasis hypercontent dapat diterapkan pada workshop atau kegiatan pelatihan lainnya yang bertujuan untuk meningkatkan kompetensi guru. Hal ini dikarenakan e-book berbasis hypercontent bukan hanya dapat digunakan sebagai bahan pelatihan melainkan juga dapat digunakans sebagai sumber belajar mandiri yang mampu meningkatkan pemahaman guru dalam berlatih mengembangkan kompetensinya khususnya dalam mengembangkan RPP saintifik berkarakter.

\section{DAFTAR PUSTAKA}

Eskawati, Y.S., \& Sanjaya, M.G.I. 2012. Pengaruh Model Pembelajaran Inkuiri Terstruktur dengan Pendekatan Saintifik Terhadap Kemampuan Berpikir Kritis dan Hasil Belajar Fisika Siswa. Jurnal Pendidikan Fisika dan Teknologi, 1(2), 46-53. ISSN: 2252-9454.

Fuada, S., Nainunis, A.I., \& Aditya, N.W. 2018. Pengembangan Buku Ajar IPS-Sejarah Digital SMP. Jurnal Teknik Informatika UIN Syarif Hidayatullah,37-48. ISSN: 1979-9160.

Ghofur, A., \& Kustijono, R. 2015. Pengembangan E-Book Berbasis Flash Kvisoft Flipbook pada Materi Kinematika Gerak Lurus sebagai Sarana Belajar Siswa SMA Kelas X. Jurnal Inovasi Pendidikan Fisika (JIPF). Vol. 04 No. 02, 176-180. ISSN: 2302-4496.

Hotimah, Ulyawati, \& Siti Raihan. (2020). 
Pendekatan heutagogi dalam pembelajaran di era society 5.0. Jurnal Ilmu Pendidikan, 1(2), 152-159.

Humairoh, F., \& Wasis. 2015. Pengembangan E-Book Interaktif Berbasis Salingtemas (Sains, Lingkungan, Teknologi, Masyarakat) pada Materi Fluida Dinamis untuk Meningkatkan Pemahaman Konsep Siswa dan Penerapannya. Jurnal Inovasi Pendidikan Fisika (JIPF), 4(2). 69-75 ISSN: 2302-4496.

Mark, Frydenberg, Diana, \& Andone. 2016. Creating Micro-Videos To Demonstrate Technology Learning and Digital Literacy. Journal of EmeraldInsightInteractive Technology and Smart Education, 13(4). http://dx.doi.org/10.1108/ITSE-09-20160030 .

Mawarni, S., \& Muhtadi, A. 2017. Pengembangan Digital Book Interaktif Mata Kuliah Pengembangan Multimedia Pembelajaran Interaktif untuk Mahasiswa Teknologi Pendidikan. Jurnal Inovasi Teknologi Pendidikan, 4(1), 84-96. pISSN: 2407-0963, e-ISSN: 2460-7177.

Megawati, C. 2014. Pengembangan Media Pembelajaran BIPA Tingkat Menengah Melalui E-Book Interaktif di Program Incountry Universitas Negeri Malang Tahun 2014. Jurnal NOSI, 2 (1). ISSN: 2337-8425.

Meishanti, O. P. Y. (2020). Pengelolaan Rencana Pembelajaran Semester Daring Berbasis Ruang Belajar Model Flipped LearninG. Prosiding Seminar Nasional Pendidikan ..., 260-266.

Munwarah, D. I., \& Buditjahtanto, A.P.G.I. 2016. Pengembangan Bahan Ajar E-Book pada Mata Kuliah Komunikasi Data Mahasiswa Jurusan Teknik Elektro Universitas Negeri Surabaya. Jurnal

Feedback Competence. EURASIA Journal of Mathematics, Science and Technology Education, 2018, 14(11), em1573, Doi: 10.1145/2094131.2094154.

Susanto, H., Roekhan, \& Priyatni, T.E. 2016. Pengembangan Buku Pintar Elektronik Teks Eksposisi bagi Siswa SMP Kelas VII. Jurnal Pendidikan: Teori, Penelitian, dan Pengembangan, 1(6)1017-1027. EISSN: 2502-471X.

Vassiliou, M., \& Rowley, J. 2008. Progressing the Definition of "E-
Pendidikan Teknik Elektro UNESA. 5(1), 1-5.

Munawwarah, M., Anwar, S., \& Sunarya, Y. 2017. How to Develop Electrochemistry SETS-Based Interactive E-Book?. Journal of Physics, Conf. Series 895. Doi: 10.1088/1742-6596/895/1/012112.

Nugraha, A.D. 2014. Pengembangan Media EBook Interaktif Bilingual pada Materi Pokok Kalor untuk SMA Kelas X. Jurnal Inovasi Pendidikan Fisika (JIPF), 3 (1), 1-7 ISSN: 2302-4496.

Pagarra, H., Bundu, P., Irfan, M., \& Raihan, S. (2020). Peningkatan Kompetensi Guru Dalam Mengevaluasi Pembelajaran Daring Menggunakan Aplikasi Berbasis Tes Dan Penugasan Online. Publikasi Pendidikan, 10, 260-265. http://103.76.50.195/pubpend/article/vie $\mathrm{w} / 16069$

Pratama, L. D., \& Lestari, W. (2020). Pengaruh Pelatihan Terhadap Kompetensi Pedagogik Guru Matematika. Jurnal Cendekia: Jurnal Pendidikan Matematika, 4(1), 278-285. https://doi.org/10.31004/cendekia.v4i1.20 7.

Puspitasari, A, \& Rakhmawati, L. 2013. Pengembangan E-Book Interaktif pada Mata Kuliah Elektronika Digital. Jurnal Pendidikan Teknik Elektro UNESA, 2(2).

Raihan, S., Haryono, \& Ahmadi, F. (2018). Development of Scientific Learning EBook Using 3D Pageflip Professional Program. Innovative Journal of Curriculum and Educational Technology, 7(1), 7-14.

Rodríguez, M.L., Alonso, P., Muñiz, R.J.L., Coninck, D.K., Vanderlinde, R., \& Valcke, M. 2018. Exploring the Effectiveness of Video-Vignettes to Develop Mathematics Student Teachers' book, EmeraldInsight Journal-Library Hi Tech, 26(3) 355-368, DOI: https://doi.org/10.1108/0737883081 0903292.

Wicaksono, P. N., Kusuma, I. J., Festiawan, R., Widanita, N., \& Anggraeni, D. (2020). Evaluasi penerapan pendekatan saintifik pada pembelajaran pendidikan jasmani materi teknik dasar passing sepak bola. Jurnal Pendidikan Jasmani Indonesia, 16(1), 41-54. 